\title{
The moderating effect of influencer on the causal map of mutual information, coproducer and customer value: a thematic analysis of messages posted by brand communities
}

\author{
Intaka Piriyakul ${ }^{1}$ (D) $\cdot$ Rapepun Piriyakul ${ }^{2}$
}

Revised: 4 February 2021 / Accepted: 13 July 2021 / Published online: 6 August 2021

(c) The Author(s), under exclusive licence to Springer Nature Limited 2021

\begin{abstract}
The COVID-19 pandemic forced customer behaviour to shift from partial online searching and buying to full use of online services. Most of the products shipped must be assembled or adjusted for personal consumption. With different needs, customers learn to customize their consumption into an experience that is more trustworthy and practical than using an influencer. This research aimed to investigate the effect of an influencer moderating the path between the coproducer and brand's mutual information. To fulfil this objective, we collected Thai customers' message posts from 50 brands' fan pages in 2020. The data preparation process used word segmentation and keyword relevance identification. Finally, the data set of 300 vectors with four measurement variables, including coproducer, influencer, mutual information, and customer value, was analysed by PROCESS Model 7 in SPSS. The results showed that the antecedent variables have positive effects on customer value, with the exception of the influencer moderating variable, which has a negative coefficient of $-0.055(p<0.1)$. Since the moderating effect of influencers has decreased the indirect effect on customer value, traditional influencer marketing must be improved to support customers who engage in expertise consumption as coproducers.
\end{abstract}

Keywords Influencers · Customer coproducer · Mutual information · Customer value

\section{Introduction}

The rapid change of unpredictable external factors, such as natural disasters and an epidemic, cause a firm's survival strategy to adapt. As a result, consumers have adapted their behaviour from physical interaction to virtual interaction (Füller 2010; Yi and Gong 2013). The ability to access information and buy products/services online is efficient for customers. Additionally, many companies have established technology-based platforms or virtual customer environments to partner with their customers in innovation and value creation.

Intaka Piriyakul

intaka@hotmail.com

Rapepun Piriyakul

rapepunnight@yahoo.com

1 Faculty of Business Administration for Society, Srinakharinwirot University, Bangkok, Thailand

2 Faculty of Science, Ramkhamhaeng University, Bangkok, Thailand
In addition, the most popular business channel to express customers' needs and demands is the brand fan page community. This virtual community provides data, information, and knowledge from four players: influencers, customers, consumers, and product owners (Nambisan and Baron 2007; Nambisan and Nambisan 2008). The dual role of an influencer is possessing the expertise to recommend product and share knowledge to customers/consumers and being a brand agent that drives a brand's message to reach the target segment (Freberg et al. 2011). Customers/consumers' interaction with the community is to communicate with each other and provide commendations and recommendations for brand product improvement based on their experience (Ahearne et al. 2005). This evidence forces the creation of marketing strategies to support and mentor the virtual brand community to maintain customer value and increase the number of active customers (Mathwick 2006). A product's firm has the responsibility to participate in communal activities; also manages effective customer relationships, such as feedback; and recognizes the customers' experience during product design. The foundation of a product design via the customers' experience is based on the mobile CRM (customer 
relationship marketing) (Rodriguez and Boyer 2020) and the customers' involvement to enhance product value (Vries et al. 2012). According to the study of Hille et al. (2015), consumers do not trust information from the brand itself, but they trust the bloggers and social media peers that they follow.

The virtual community and the related component are issues that deserve attention as a new revaluation of brand management from the front line (Soltani and Navimipouret 2018). A recent popular study focused on the interactions among members that can influence the choice of brands and impact brand loyalty (Bagozzi and Dholakia 2006). Additionally, the research of Soltani and Navimipouret (2018) concentrated on customer retention based on virtual CRM. Regarding the analyses and technical viewpoints, many studies have used statistical tests, SEM, and neural networks to answer their research questions. Kuchmaner et al. (2019) constructed a conceptual framework with four factors: perceived network centrality as an independent factor, psychological ownership as a mediator, likelihood to punish the brand as a dependent factor, and perceived network density as the moderator between the mediator and dependent factor. In 2018, ZeySoltani and Navimipouret (2018) conducted the research titled "The impact of the customer relationship management on the organizational performance" and used PLS to confirm the research model. Previous work on the influencer issue has reported the impact of social media influence on many dimensions, i.e., purchase intentions, customer attitude, product engagement, brand loyalty, market share, and brand image (Lim et al. 2017). According to the study of Lim et al. (2017), the use of social media influencers contributes more trustworthiness and knowledge due to their amiability in building a rapport with consumers, especially for supporting buying decision making.

Most of the few works on an influencer's role as a moderator in social media marketing found a positive influence. Consumers' learning of how to see through these marketing strategies over recent years leads to a decline in brand engagement (Holt 2002). Consequently, from a customer's perspective, being a coproducer is driven by needs, consumption experience, and self-esteem theory (Hsieh and Chang 2016). The research problem regarding the interactive effect of a blogger or an influencer on a customer coproducer through mutual information has the same direction as that from mutual information to customer value. The results of the study led to the application of a new way of positioning the related factors, including customer coproducers, mutual information, and influencers, to enhance customer value. To obtain a better understanding of the virtual community in this research, we develop evidence based on the Facebook brand pages and virtual communities of ice cream shops, coffee shops, and restaurants in Thailand using an exploratory study.
This study, therefore, attempts to provide additional insights into the interaction between a customer as a coproducer and mutual information through customer value by examining the effects of the moderator and other factors in the conceptual network. To conduct hypothesis testing, we collected sample data from the Thai customers' post data.

The structure of the remainder of this paper is as follows. First, we review the literature about customer coproducers, mutual information, customer value, and influencers. Second is the methodology and results. Finally, the discussion, limitations, and future work are given.

\section{Literature review and hypothesis development}

\section{Customer coproducers}

Customer cocreators or coproducers were first mentioned in the late 1990s and used in the sense of being together to design or produce a product (Füller 2010; Ramaswamy 2009). Later, this concept was applied to the service business, which is widely accepted (Wikström 1996). Marketing scholars such as Prahalad and Ramaswamy (2004) discuss the concept of engaging businesses with customers as creating product value. Customers are participants in the product design activities. The study of Vargo et al. (2008) indicated that a customer's activity resulted in value for the customer from their impression of the experience from the use of the product and supported the design and creation of the product. The foundation of customer coproducers develops from customer experience and customer relationship management. Füller (2010) and Ramaswamy (2009) explained that the collaboration of customers and product owners in product design is a process that creates mutual value and satisfies customers' needs. The benefits of customer coproducers support customization strategies, such as obtaining goods/services that are suitable for consumption based on demographics and economics or the ability to set suitable usage telephone packets or designing food for elderly customers with health problems (Ramaswamy 2009). Vargo and Lusch (2004) assessed customer coproducers from the perspective of value creation. This perspective previously examined the product dimension (good-dominant logic) to focus on service-dominant logic, which refers to human resource management in the service industry. Then, customer coproducers in service design were widely studied (Prahalad and Ramaswamy 2004; Rizcky et al. 2014). Using a customer's experience to help design products not only fulfils self-consumption but also satisfies self-esteem. Regarding the product-centric dimension, these responses raise engagement and customer value (Füller 2010). 
Social media and mobile capabilities are key factors in creating virtual groups and leading to relational engagement including customer to customer, customer to firm, and customer to blogger. The work of Rizcky et al. (2014) examined the "cocreation scale" measurement scale and concluded that there were four components: (1) Multiple channels for supporting flexible communication, (2) Augmented options to enhance coproductive activities, (3) Protocol for the streaming transaction process (i.e., B2B marketing) and (4) Relationship management to bind firms and customers via tangible and intangible assets. Finally, to obtain opportunities in the competitive market and address the struggle caused by unpredictable crisis factors, efficient online marketing management is the best solution, especially in the technology disruption era (Dholakia et al. 2004). Thus, a firm must focus on these four components and manage an organizational capability to meet their goals.

Several researchers affirm that this paradigm may be very useful in understanding why consumers participate in virtual communities (Füller 2010; Rizcky et al. 2014). Additionally, the rapid growth of social media interaction signifies people's needs: physical needs including consumption and emotional needs including a sense of belonging to the community by sharing and recommending beneficial information. With these activities, mutual information as a source of knowledge for a brand's virtual community is a widely wise used space for other communities. Customer knowledge accumulates from two access methods: accepting (learning, reading, or listening) from different sources and learning by doing (experience of purchasing and consuming). For this reason, customer experience has two views: positive regarding the product characteristics of user satisfaction and negative regarding some characteristics being inapplicable to the user (Yoo et al. 2010; Majchrzak et al. 2013). Regarding the positive aspect, customers have the potential to strengthen the brand's community. The negative result may be sending the problem to this community or sometimes removing or posting a comment to improve the product. However, loyal customers who have been engaged with this brand for a long time always communicate with a firm's product as a designer to maintain and improve the product (Franke Merle et al. 2010).

Businesses that achieve success using a customer coproducer strategy include Lego, McDonald's, Heineken, and Vicky Foods. Lego has a community where consumers can contribute ideas for the brand's new models. The company, therefore, saves time and money in market research as cocreation identifies which products will be well received by consumers. Apart from renewing their menu, McDonald's was successful at empowering customers to codesign their perfect burger whereas Vicky Foods collaborated with customers to be coproducers of environmentally friendly and healthier products (Innovators 2020). According to the previous literature and the success of the customer coproducer tactic, we cannot overlook the brand community as a virtual touchpoint of member activities. This touchpoint looks like a big gallery with many members chatting, sharing knowledge, and interacting with each other while joining activities together. Since most of them are groups that use the same brand, this leads to the opportunity to increase customer value (Rizcky et al. 2014). Customer coproducers can be measured both qualitatively and quantitatively, such as how often, what message, and the degree of involvement in product design (Yoo et al. 2010; Majchrzak et al. 2013).

The touchpoint is an information tank for supporting a brand's perceived value and buying process. In addition, customers who act as coproducers want to offer their expertise and engagement in the community (Porter and Donthu 2008). These relationships among individuals and within brand communities are a source of social capital (Bhandari and Yasunobu 2009). As discussed previously, a coproducer is an antecedent of mutual information and customer value related to social exchange theory and social capital theory (Chu and Kim 2011). Customers as coproducers adopt social exchange theory as the source of information while social capital theory supports the value added of mutual information. Social capital theory was developed from the gap of economic value to recognize the potential roles of social and cultural dimensions (Bilig 2000). This theory is particularly rooted in the notions of commitment, trusts, norms, and informal networks; and it believes that social relations are valuable resources. The significant role of social exchange theory will be further discussed in the topic of the moderating effect of influencers in the network framework. Thus, customer engagement in brand development is positive for mutual information and customer value, as hypothesized.

H1 Customer coproducers are positively related to mutual information.

H2 Customer coproducers are positively related to customer value.

\section{Mutual information}

Mutual information is a virtual destination or knowledge portal in which customers/consumers exchange their experiences to describe a product or brand in various dimensions, combine the experiences together and allow people to use the information to support purchases and consumption (Vries et al. 2012). The mutual information consists of posts from the brand owner, feedback from group members, knowledge sharing, and product opinions belonging to knowledgeable people known as bloggers or gurus. There are many forms of information and knowledge, including messages or multimedia. Information from this source is 
used for various purposes such as health, happiness, purchasing or effectively using products, and recommendations for product design (Bagozzi and Dholakia 2006). Mutual information is developed from probability theory and used by Lin et al. (2004) in their study on virtual team management in the context of knowledge for all members. Mutual information specifies the qualitative and quantitative value of information. High mutual information indicates a large reduction in uncertainty, low mutual information indicates a small reduction in uncertainty, and zero mutual information between two random variables means that the variables are independent (Archer et al. 2013). The two random variables in information theory are equivalent to the messages from two members of the community. Due to a large amount of relevant and irrelevant data in the virtual or brand community, the content analysis of heuristic or system approaches is a way to enhance mutual information (Hsieh and Shannon 2005).

One indicator that signifies an effective brand community is a knowledge portal for anyone who wants to be aware of a product and brand before the purchase stage (Porter and Donthu 2008). To strengthen the brand knowledge centre, five important aspects of customer enthusiasts for managers interested in creating and running a vibrant and influential brand community of customers are the following: (1) empowering customers, (2) welcoming diversity, (3) providing efficient tools, (4) developing a synergistic market program, and (5) supporting customer enthusiast-run brand communities (Knippenberg and Schippers 2007). According to the research of Bart et al. (2005) and Bronnenberg et al. (2016), online marketing should raise the contribution of the brand community as an increasingly dominant role in information acquisition, product evaluation, and selection. Therefore, without favourable initial trust in the mutual information basis, customers have no confidence in the brand (Bart et al. 2005; Hollebeek and Macky 2019). The consequences of the associated factors in the virtual community, especially the brand fan page, are shown in the stakeholder's interaction diagram in Fig. 1.

H3 Mutual information is positively related to customer value.

Fig. 1 The relationship of members in virtual communities used to construct mutual information

\section{Customer value}

To maintain and extend a customer's long live value as a business achievement by enhancing customer value, Hogan et al. (2003), and Ho et al. (2014) defined customer value as the amount of benefits assessed or measured for a product or a service's worth compared to its possible alternatives. This determines whether the customer feels like they received sufficient value for the price they paid for the product/service. If customers feel that the total costs of an item outweighs its benefits, they will regret their purchase, especially if there is a competitor that makes a better offer for a similar product or service. Most businesses use the financial value of customer value measurement. However, marketers do not remember that customers give more to their companies than just what is listed on the price tag. There are also time costs, energy costs, and emotional costs that customers weigh when making a buying decision (Colgate and Lang 2001).

There are many types of benefits that influence buying decisions. Some examples include tangible and intangible benefits-such as how the product will help them satisfy their needs and goals - as well as image benefits—such as how owning this product or service will change one's social status in the eyes of their peers and colleagues (Bagozzi and Dholakia 2006). Underlying from the utilitarian perspective, the broader theoretical framework of perceived value has been developed by Anderson (1973) and Sheth et al. (1991); in the expectancy theory and the theory of consumption value which are based on the customer decision or choice whether to buy or not to buy, to choose between two products or to choose one particular brand over another. Finally, the costs and benefits are the preliminary foundation to calculate customer value. The value assessment of benefits is based on product quality, the ability to satisfy needs, perceived brand value, and the brand's association. Furthermore, the total customer costs is the sum of the product price, onboarding costs, the costs of accessing the product, learning costs, relational costs (the relationship between a customer and service provider), and risk costs (Jones et al. 2002; Lilien et al. 2017). The difference between customer benefits and customer costs is calculated using the formula:

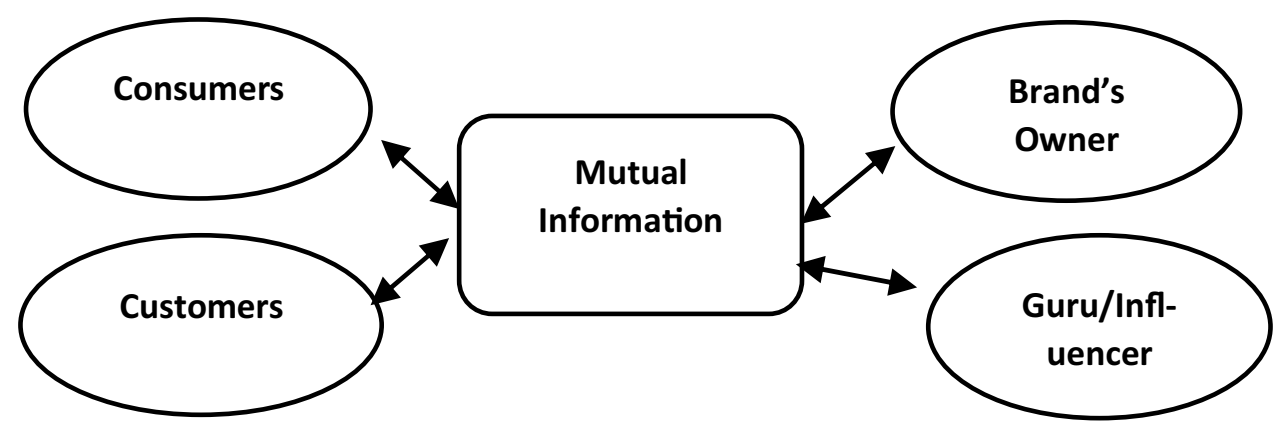


Customer Value $=$ Total Customer Benefits - Total Customer Costs,

$\mathrm{CV}=B-C$.

However, tangible and intangible elements such as brand reputation, social status, and service convenience should be compared to costs such as time investment, emotional stress, and visible commitment (Jones et al. 2002; Lilien et al. 2017). Additionally, customer value varies based on the different segments of the customer. Since each customer is different and has specific needs, goals, and expectations, the marketer should identify a "good value" for the target customer (Ansari and Mela 2003; Gupta et al. 2004).

\section{Influencers}

Most marketing strategies refer to influencer marketing, which emphasizes the use of expertise and a well-known person to drive a brand's message to reach the target segment (Lim et al. 2017; Smart Insights 2017). This strategy has proven to be an efficient technique and has been shown to increase sales and retention (Kumar et al. 2010; Lim et al. 2017). In recent years, the influencer marketing industry is on track to be worth up to $\$ 15$ billion by 2022 , up from as much as $\$ 8$ billion compared to 2019 , according to Business Insider Intelligence estimates based on Mediakix data (Business Insider 2020). Additionally, the statistics given in the report are the following: "Every social platform attracts influencers to some degree, but Instagram is the gold standard for the group. And nearly four in five (79\%) brands predominantly tap Instagram for influencer campaigns, compared with Facebook (46\%), YouTube (36\%), Twitter (24\%), and LinkedIn (12\%), per Influencer Marketing Hub" (Business Insider 2020).

Influencers or those with other generic names such as "celebrities", "bloggers", "vloggers", "Youtubers", and "KOLs (key opinion leaders)" are people who have built a reputation for their knowledge and expertise on a specific topic (Uzunoğlu and Kip 2014; Liu-Thompkins and Rogerson 2012). They make regular posts about that topic on their preferred social media channels and generate large followings of enthusiastic, engaged people who pay close attention to their views. The power of an influencer's message affects the purchasing decisions of others because of their experience, knowledge, position, or relationship with his/her audience (Pradhan et al. 2016; Lim and Cheah 2017). However, influencers are not merely marketing tools but rather social relationship assets with which brands can collaborate to achieve their marketing objectives. There are many classifications of influencers. The most common methods are numbers of followers, types of content, and level of influence. The other paradigm related to the categories is reached-as a general rule, targeted reach, cost-effectiveness, engagement, authenticity, and accessibility all increase as the follower count decreases; and niche brands can leverage relevant niche influencers to more intentionally target audiences (Harrigan et al. 2012; Bobkowski 2015).

Creating good-quality content represents a significant feature of a social influencer. This is due to the superior content that engages in a game with the consumers' beneficial effects to reduce marketers' workload and accomplish a firm's goal. Consumers will be able to quickly capture messages if an endorser is well-known, professional, and attractive, which in the end can gather a brand image and consumer buying interest in the campaigned products (Chi et al. 2009). Most previous studies on the issue of influencer marketing concluded that the strategy of the company was successful at building awareness and gaining returns (Foong and Yazdanifard 2014). However, like any emerging campaign strategy, influencer marketing has both positive and negative effects. From the influencer's perspective, there are two different collaborations with companies: earned and paid collaborations (Lee 2017). Earned collaborations are when the influencer promotes a brand without having any contact with the company. Paid, however, is when companies sponsor or pay an influencer to promote their brand. The latter is of particular interest in this paper. In paid influencer marketing, monetary values seem to be the main driver for the influencer, even though influencers themselves usually state that brand values are important for them to enhance the brand (Weiss 2014; Iurillo, 2019). In general, interpersonal trust between the members of a brand's community is based on the nonhidden commercial agenda. Additionally, customers' considerable consumption of a product's brand leads to a lack of trust in a paid influencer. Finally, a suggestion or recommendation from an influencer and customer coproducer will interact and cause a negative effect through mutual information. With the rapid change of technology and the growth of information, influencer marketing can be potentially harmful to communities and among customers/ consumers in the context of commercialism. Much research shows that the effects can be positive for short time marketing. Leaning on Holts's research (Holt 2002), the risk is that companies soon will exploit interpersonal trust with influencer marketing, which will decrease the effect. Therefore, companies must manage customers' coproducers effectively and gain this strategy to increase long-term relationships with their customers.

Influencer marketing success depends on communication theory, which is a network foundation. The information is disseminated within a network of connected entities. Inside this network, there are clusters; and within the clusters, there are central nodes of influence. These nodes are well connected and help transmit messages to a wider audience. Consequently, powerful programs can be established that target influencers based on proximity 
of trust rather than status in the community. As social media allow more people to achieve fame and influencer status, social media quickly have become oversaturated with influencers. From the audience's perspective, keeping up with all of the content (especially sponsored content) coming from the influencers they follow is impossible (Chi et al. 2009). The same influences that capture audience attention may not hold that attention tomorrow. Everyone knows that it is not always a given that influencers use (or even known) the products or services they endorse on social media (Lee 2017). While many brands do not seem to care if an endorsement is truly authentic, there may be a problem that audiences able to interpret influencer endorsements as inauthentic or misleading, and both the brand and influencer may lose credibility. A study from Forrester (2018) reports that $47 \%$ of customers are tired of influencer content that appears inauthentic and $62 \%$ of customers believe that influencer endorsements take advantage of impressionable audiences (Iurillo 2019).

According to Holt (2002) and previous studies, marketing techniques have changed roughly every decade for the past 60 years. The common denominator in these changes is that as the majority of brands imitate a certain technique or marketing strategy, the less efficient the strategy. Due to this fact, consumers learn how to see through these techniques and strategies. With the increase in brands engaging in influencer marketing in recent years, we are no longer exploring influencer marketing; rather, we have started to exploit this issue as a moderating variable in the theoretical framework (see Fig. 2).

The extent to which customer coproducers and influencers enhance mutual information leads to two research hypotheses: (1) the interaction of influencers and customer coproducers has a positive or negative impact on mutual information, and (2) the different strengths of influencers and customer coproducers occur through mutual information and customer value.

H4 The interaction of coproducers and influencers impacts mutual information.

\section{The moderating effect of influencer in the network framework}

A moderator is a variable that affects the strength of the relation between the predictor and the criterion variable. Moderators specify when a relationship will hold. A moderator can be qualitative (e.g., sex, race, class) or quantitative (e.g., level of reward). The moderating variable is typically an interaction term in statistical models. For instance, assume that marketers are evaluating the effects of a new brand promotion campaign. They vary the amount of promotional investment (predictor/independent variable) and measure their market share after the new campaign (criterion/dependent variable). They find that at low volume, there is a small association between customer satisfaction and purchase level; but at a high volume of promotion, there is a huge association between customer satisfaction and purchase levels. The promotion moderates the association between investment volume and market share. Marketing scholars, in particular, have exhibited an increasing interest in moderator variables, especially concerning the customer satisfaction construct and the satisfaction-loyalty link (e.g., Bolton et al. 2004; Olsen et al. 2005; Evanschitzky and Wunderlich 2006).

The importance of moderators arises from their ability to enhance the understanding of the relationships between relevant independent variables and dependent variables, as well as seemingly established relationships. For example, the studies of Mittal and Kamakura (2001) found that several variables, such as the nature of the product/service, the type of industry, and the competitive environment, influence the satisfaction-loyalty relationship. Homburg and Giering (2001) examined the moderating effect of three demographic (gender, age, and income) and two psychographic (involvement and variety-seeking) factors on the link between satisfaction and loyalty. Regarding the work of Homburh and Giering (2001), using multigroup SEM, we found that age and income were moderating variables. They showed that involvement has a positive moderating effect on the satisfaction-loyalty link. Consequently, Magi (2003) also examined the moderating effect of individual difference variables, such as bargain-hunting propensity or apathy, with a focus on customer share in terms of both spending
Fig. 2 The theoretical framework: customer coproducers as an antecedent factor, mutual information as a mediator, customer value as a dependent factor, and influencers as a moderator

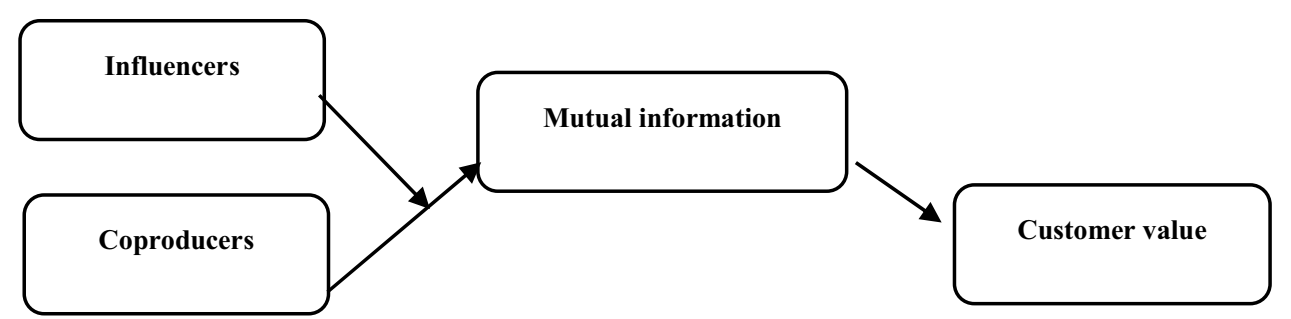


and the number of visits to the primary store. In the study, satisfaction represents a more important determinant of the share of low-income consumers, and shoppers' personalized shopping orientation moderates the satisfaction-share relationship such that shoppers who value social interactions with store personnel are less sensitive to satisfaction decreases. According to the economic perspective, social exchange theory views exchange as a social behaviour that may result in both economic and social outcomes. (Burns 1973; Lambe et al. 2001) Social exchange theory has been generally analysed by comparing human interactions with the marketplace. From this perspective, every individual seeks to maximize his wins (Blau 1964). Blau (1964) stated that once this concept is understood, it is possible to observe social exchanges everywhere, not only in market relations but also in other social relations such as friendship.

The social exchange process brings satisfaction when people receive fair returns for their expenditures. The major difference between social and economic exchange is the nature of the exchange between the parties. Unlike an economic exchange, the elements of social exchange are quite varied and cannot be reduced to a single quantitative exchange rate. Social exchanges involve a connection with another person, involve trust and not legal obligations, are more flexible, and rarely involve explicit bargaining (Baxter and Braithwaite 2008). Regarding the perception of customers with high product/service consumption experiences, there is a conflict of interest with the information interchange between the statuses of customers and influencers in embedded commercial benefits (Forrester 2018).

A moderating variable issue in marketing analytic applications such as Homburh and Giering (2001) showed that involvement had a positive moderating effect on the satisfaction-loyalty link, but in a subsequent study, Homburh and Giering were unable to confirm this moderating effect (Homburh and Giering 2001). More recently, most studies have considered the customer profile including gender, age, and income as moderators (Mithal and Kamakura 2001; Walsh et al. 2008). Along with age, some research fails to show a significant moderating effect of gender on satisfaction and loyalty relationships, such as Walsh et al. (2008). However, many studies have proposed gender as one of the moderating variables (e.g., Mithal and Kamakura 2001). This argument is based on social role theory, which suggests that different groups of people behave differently in different situations and take on different roles. Regarding the other dimension of the moderating variable, Rodriguez and Boyer (2020) proved that sales process capability moderated the relationship between $\mathrm{mCRM}$ and collaboration.

To analyse the moderating role of influencers on the path between coproducers and mutual information, the significant roles of information theory and commitment-trust theory must be synchronized. Based on the study of consumer choice model behaviour (Bettman 1979), consumers may reduce their search efforts by narrowing their choice sets or relying on some important key information cues, such as their past behaviour. Following this line of reasoning, we can assume that continuous satisfaction correlates negatively with search and costs, and slight variations in satisfaction levels do not necessarily affect loyalty behaviour. Rapid changes in technology devices and communication platforms enhance customer knowledge acquisition and the self-determination of information (Lilien et al. 2017). Moreover, no hidden commercial agenda using mutual information from the knowledge portal is constructed with customers' brand involvement via a social media channel (Bart et al. 2005; Hollebeek and Macky 2019). From the commitment-trust theory perspective, the conceptualizations of relationship commitment in social exchange among the members in the community are the activities to maintain information interchange and update mutual information to support brand community consumption (Vries et al. 2012). Furthermore, trust is defined as a willingness to rely on an exchange partner's reliability and integrity. The literature on trust suggests confidence on the part of the trusting party from the value of belief, which is associated with qualities such as consistency, competence, honesty, fairness, helpfulness, and benevolence (Atman and Taylor 1973). Like commitment, trust has also been studied widely in the social exchange literature; for example, in organizational behaviour, the "norms of trust" are considered a characteristic distinguishing management theory from an economic view (Barney 1990). Furthermore, in communications, a key construct was originally defined as the trust of the speaker by the listener (Hovland et al. 1953).

This study, therefore, seeks to provide additional insight into the relationship between customer coproducers and mutual information by examining the effects of influencers as a moderator. To investigate the effects of the proposed moderator, we use PROCESS Model 7 (Hayes 2013, 2016) and structural equation modelling (SEM) to assess the role of an influencer. When the moderating influence is measured continuously, this influence is generally modelled by creating a new variable that is the product of the variable that is being moderated (coproducer) and the variable that is moderating (influencer). This interaction term (coproducer $\times$ influencer) is then entered into the regression equation after the linear main effects on the outcome (mutual information) of the moderating (influencer) and moderated variables (coproducer) are estimated. If the effect of coproducer $\times$ influencer is significant, then the effect of coproducer on mutual information is dependent upon the levels of influencer. Aiken and West (1991) describe simple procedures for taking the estimated regression weights from the full equations and plotting an amount of implied regression to provide a visualization of the moderated effect. 
Most previous studies were based on quantitative analysis using questionnaires constructed from related literatures (Rodriguez and Boyer 2020; Weiss 2014). A sample of customers/consumers was selected as the unit of analysis. The validity of this data collection technique has been doubted due to the willingness of the respondents to provide false data. Therefore, to build credibility, this work used message posts on fan page brand communities. The anatomy of a post consists of either a picture, a video clip, a message or other symbols. The message is a language string with a variable length. A message has many styles, such as a request, a recommendation, a promotion, motivation and a complaint. Using the messages for this study is the best way to understand the actual needs and wants of customers.

\section{Methodology}

In this section, we illustrate the empirical study as two tasks: data preparation and data analysis.

\section{Data preparation}

Due to the characteristics of Thai messages, the data preparation is divided as follows.

\section{Step 1}

The messages from customer posts on the Thai fan page on Facebook were collected from September 2019 to September 2020 and included fifty product types (e.g., ice cream,

\section{Step 2}

Each vector (i.e., the term "period ${ }_{\mathrm{i}, \mathrm{A}}$ " is a vector of period $i$, and "A" is a product brand) consists of a number of posted messages, which can be represented as follows:

$\operatorname{period}_{i, A}=\left\{P_{1}, P_{2}, \ldots, P_{k}\right\}$,

where $P_{j}$ is the $j$ th posted message, and $k$ is the number of posts.

\section{Step 3}

Manually, the message posts of period $_{i, A}$ was classified into four groups, including $\mathrm{CCO}, \mathrm{INF}, \mathrm{MUI}$, and CUV, as the following sample:

$\left.\operatorname{period}_{i, A}=\left\{\operatorname{CCO}\left(P_{1}, P_{3}, P_{5}\right), \operatorname{INF}\left(P_{4}, P_{6}\right)\right\}, \ldots, \operatorname{CUV}\left(P_{9}, P_{7}\right)\right\}$,

where $\operatorname{CCO}\left(P_{1}, P_{3}, P_{5}\right)$ represents the three message posts $\left(P_{1}, P_{3}, P_{5}\right)$ of CCO.

\section{Step 4}

After step 3, the message post $\left(P_{j}\right)$ was passed to two subtasks: word segmentation and keyword identification.

\section{Step 5}

To measure the variables in each period of the brand, we constructed four word sets (type sets). The sets were composed of the relevant activity concept of the study variables. The quantified sets were listed as the following:

Influencer $=\{\langle$ suggest $\rangle\langle$ cheer $\rangle\langle$ support $\rangle\langle$ promote $\rangle\langle$ recommend $\rangle,\langle$ buy $\rangle$, $\langle$ claim $\rangle,\langle$ hide $\rangle,\langle$ boost $\rangle,\langle$ encourage $\rangle,\langle$ guide $\rangle\}$,

Coproducer $=\{\langle$ match $\rangle\langle$ with $\rangle,\langle$ couple $\rangle,\langle$ enhance $\rangle,\langle$ mix $\rangle,\langle$ modify $\rangle,\langle$ design $\rangle,\langle$ test $\rangle\}$,

Mutual information $=\{\langle$ benefit $\rangle\langle$ utilization $\rangle,\langle$ enhance $\rangle,\langle$ upgrade $\rangle,\langle$ reduce $\rangle,\langle$ security $\rangle$,

$\langle$ usability $\rangle,\langle$ control $\rangle\langle$ reuse $\rangle\langle$ impact $\rangle\langle$ safe $\rangle\langle$ offer $\rangle\}$,

Customer value $=\{\langle$ need $\rangle,\langle$ want $\rangle,\langle$ happy $\rangle,\langle$ satisfaction $\rangle,\langle$ commit $\rangle,\langle$ recognize $\rangle$, $\langle$ awareness $\rangle,\langle$ repurchase $\rangle,\langle$ joy $\rangle,\langle$ recall $\rangle,\langle$ like $\rangle\}$.

coffee, pizza, food restaurants, and bakeries). The messages for each brand product were segmented into six periods with 2 months for each period; and finally, the data set consisted of 300 vectors (records).
The sets were constructed based on a customized product. To clarify the data set, we give some observed messages. One message post gave a recommendation "to eat ice cream 
Table 1 Data set

\begin{tabular}{|c|c|c|c|c|c|c|c|}
\hline Vector (record) & Product & Brand & Period & $\begin{array}{l}\text { No. of words in } \\
\text { influencer }(i=1)\end{array}$ & $\begin{array}{l}\text { No. of words in } \\
\text { coproducer }(i=2)\end{array}$ & $\begin{array}{l}\text { No. of words in mutual } \\
\text { information }(i=3)\end{array}$ & $\begin{array}{l}\text { No. of words in } \\
\text { customer value } \\
(i=4)\end{array}$ \\
\hline 1 & Ice cream & A & Period 1 & $n_{1,1}$ & $n_{2,1}$ & $n_{3,1}$ & $n_{4,1}$ \\
\hline 2 & Ice cream & A & Period 2 & $n_{1,2}$ & $n_{2,2}$ & $n_{3,2}$ & $n_{4,2}$ \\
\hline 3 & Ice cream & A & Period 3 & $:$ & $:$ & $:$ & $:$ \\
\hline 4 & Ice cream & A & Period 4 & : & : & : & : \\
\hline 5 & Ice cream & A & Period 5 & $:$ & $:$ & $:$ & $:$ \\
\hline 6 & Ice cream & A & Period 6 & $n_{1,6}$ & $n_{2,6}$ & $n_{3,6}$ & $n_{4,6}$ \\
\hline \multicolumn{8}{|l|}{ : } \\
\hline 300 & Restaurant & M & & $n_{1,300}$ & $n_{2,300}$ & $n_{3,300}$ & $n_{4,300}$ \\
\hline Min & & & & $\operatorname{Min}_{1}$ & $\operatorname{Min}_{2}$ & $\operatorname{Min}_{3}$ & $\operatorname{Min}_{4}$ \\
\hline Max & & & & $\operatorname{Max}_{1}$ & $\operatorname{Max}_{2}$ & $\operatorname{Max}_{3}$ & $\operatorname{Max}_{4}$ \\
\hline
\end{tabular}

Remark: the brand is as an alias name

Table 2 Experimental data

\begin{tabular}{lllll}
\hline Record & $\begin{array}{l}\text { Influencer } \\
\text { score }\end{array}$ & $\begin{array}{l}\text { Coproducer } \\
\text { score }\end{array}$ & $\begin{array}{l}\text { Mutual informa- } \\
\text { tion score }\end{array}$ & $\begin{array}{l}\text { Customer } \\
\text { value } \\
\text { score }\end{array}$ \\
\hline 1 & 2 & 3 & 4 & 3 \\
2 & 1 & 4 & 5 & 4 \\
$:$ & $:$ & $:$ & $:$ & $:$ \\
300 & $:$ & $:$ & $:$ & $:$ \\
\hline
\end{tabular}

matched with mango" while another post was "eating ice cream coupled with sticky rice makes me happy".

\section{Step 6}

To explain how to calculate the frequency of the study variables, we demonstrate the following:

Let period pi,A $=\left\{\mathrm{CCO}\left(P_{1}, P_{3}, P_{5}\right), \operatorname{INF}\left(P_{4}, P_{6}\right\}, \operatorname{MUI}\left(P_{2}\right)\right.$, $\left.\operatorname{CUV}\left(P_{9}, P_{7}\right)\right\}$

$P_{1}=\{\langle$ test $\rangle,\langle$ run $\rangle,\langle$ match $\rangle\}$,

$P_{3}=\{\langle$ design $\rangle,\langle$ enhance $\rangle,\langle$ sick $\rangle\}$,

$P_{5}=\{\langle$ play $\rangle,\langle$ enhance $\rangle,\langle$ go $\rangle\}$.
The numbers of words in $P_{1}, P_{3}$, and $P_{5}$ that occurred in the quantifying set $\mathrm{CCO}$ were 2,2 , and 1 , respectively. Then, the frequency of the $\mathrm{CCO}$ in the $i$ th period of brand A was 5. We applied the extraction process to generate the data set. Finally, each row vector consisted of four variables: coproducer (CCO), influencer (INF), mutual information (MUI), and customer value (CUV). Each variable or feature was the frequency of words $(1, \ldots, n)$. The data structure is represented in Table 1.

\section{Step 7}

Transform the data from step 6 to five-point scales (score) to reduce the bias from the variable length of the message post.

Table 1 shows the results of the preparation obtained from a data set consisting of 300 entities to be analysed to test the hypotheses and to investigate the moderating effects.

The criteria to convert the frequency of relevant words to analysis measurement are as follows:

(1) Compute: Interval of Scale $=\left(\operatorname{Max}_{i}-\operatorname{Min}_{i}\right) / 5=d_{i}$, where $i=1,2,3,4$

(2) $\operatorname{Max}_{i}=\operatorname{Maximum}\left(n_{i, 1}, n_{i, 300}\right)$ and $\operatorname{Min}_{i}=\operatorname{Minimum}\left(n_{i, 1}\right.$, $\left.n_{i, 300}\right)$

(3) Compute: Score $_{i, j}=k$ if $(k-1) * d_{i}<n_{i, j} \leq k * d_{i} ; k=1$, $2, \ldots, 5 ; i=1,2, \ldots, 4 ;$ and $j=1,2, \ldots, 300$
Table 3 Outcome variable: MUI (Model Summary: $Y=\mathrm{CUV}, X=\mathrm{CCO}$, and $M=\mathrm{MUI})$

\begin{tabular}{lllrlrr}
\hline & Coefficient & SE & $t$ & $p$ & \multicolumn{1}{l}{ LLCI } & ULCI \\
\hline Constant & 0.001 & 0.046 & 0.016 & 0.986 & -0.089 & 0.091 \\
CCO & 0.609 & 0.046 & 13.239 & 0.000 & 0.518 & 0.699 \\
\hline
\end{tabular}


Table 4 Outcome variable: CUV

Fig. 3 The path coefficients were assessed to examine the positive significance of hypotheses

Table 5 Outcome variable: MUI (Model Summary)

Table 6 Focal prediction: CCO $(X)$, Mod var: $\operatorname{INF}(W)$, conditional effects of the focal predictor at values of the moderator(s)

\begin{tabular}{lllllrr}
\hline & Coefficient & SE & $t$ & $p$ & \multicolumn{1}{l}{ LLCI } & ULCI \\
\hline Constant & 0.003 & 0.045 & 0.083 & 0.933 & -0.085 & 0.093 \\
CCO & 0.427 & 0.057 & 7.434 & 0.000 & 0.314 & 0.540 \\
MUI & 0.261 & 0.058 & 4.459 & 0.000 & 0.518 & 0.369 \\
\hline
\end{tabular}

${ }^{*} p<0.05, * * p<0.01$, and $* * * p<0.001$

\begin{tabular}{lcccccc} 
Coproducers \\
\cline { 3 - 7 }
\end{tabular}

Product terms key: Int_1: $\mathrm{CCO} \times \mathrm{INF}$, and $R=0.651^{* * *}$

\begin{tabular}{lllllll}
\hline INF & Effect & SE & $t$ & $p$ & LLCI & ULCI \\
\hline-0.809 & 0.394 & 0.064 & 6.127 & 0.000 & 0.267 & 0.521 \\
0.181 & 0.339 & 0.068 & 4.996 & 0.000 & 0.205 & 0.473 \\
1.173 & 0.285 & 0.0831 & 3.429 & 0.000 & 0.121 & 0.448 \\
\hline
\end{tabular}

$* p<0.05, * * p<0.01$, and $* * * p<0.001$

Fig. 4 The analysis framework: customer coproducer as an antecedent factor, mutual information as a mediator, customer value as a dependent factor, and influencer as a moderator

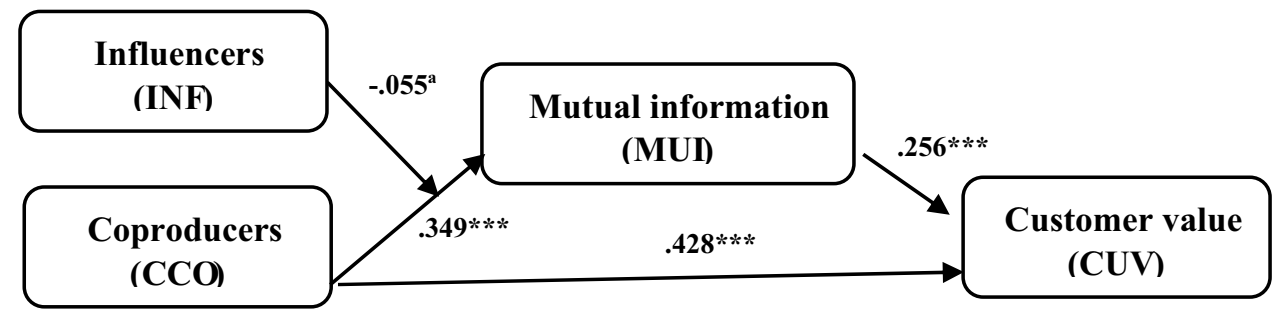

An example of data set transformation is shown in Table 2.

\section{Data analysis}

The data standard normalization was preprocessed before testing the conceptual model using PROCESS Model 7 (Hayes 2013, 2016). The testing consisted of two steps: step 1 for H1-3 and step 2 for the moderating effect.

\section{The experimental results}

The testing divided into two steps:

\section{Step 1}

This step tested hypotheses H1-3 using PROCESS Model 4, and the output is presented in Tables 3 and 4 . 
The graphical representation of the testing hypotheses (H1-3) derived from Tables 3 and 4 is illustrated in Fig. 3.

\section{Step 2}

The testing of the hypothesis and the role of the moderator of influencer were integrated in PROCESS Model 7, and the output is shown in Tables 5 and 6. The coefficients of the paths from the antecedent variables CCO and INF to MUI are 0.349 and 0.274 , respectively, while the interaction of INF and CCO (INF $\times$ CCO) is -0.055 . In addition, all of the path coefficients are significant.

The output from Table 4 shows that the interaction effect of CCO and INF increases due to INF decreasing.

The graphical representation to test hypotheses (H1-4) derived from Tables 3 and 4 is illustrated in Fig. 4.

The direct effect of CCO on CUV, $0.428^{* *}$, is highly significant. This influence value indicates that $\mathrm{CCO}$ has a large impact on CUI with a $\beta$ coefficient greater than 0.256 . Therefore, the results indicate that there may be some mediating factors behind the impulse linkage between $\mathrm{CCO}$ and CCU. Moreover, the coefficient of the influence of INF as the moderator on the path between CCO and MUI is -0.055 $(p \leq 0.10)$. This means that the influence that $\mathrm{CCO}$ has on MUI will decrease when INF is higher and lead to the decreasing value of the indirect effect on CCU. In other words, the analysis of the indirect impacts from $\mathrm{CCO}$ to MUI and from MUI to CUI had a significant relationship with the small value of INF.

The results of the analysis infer that social media groups with experienced customers who bring express the desire to be coproducers support knowledge for the community. Customers' perception of the negative side of influencers is that influencers are paid to collaborate with the brand product (Pradhan et al. 2016; Lim and Cheah 2017). Therefore, consumers learn how to see through these techniques and strategies (Holt 2002). Furthermore, customers who have long been loyal to the brand often have knowledge that is more credible than influencers (Lee 2017). Influencer marketing is a successful strategy for new customers or potential customers, but for the expert customers, the effectiveness of this technique is doubtful. Our finding on the degree to which customers are involved in producing products in the domains of study, e.g., ice cream, coffee, and restaurants, has shown that customers have different demands to satisfy their needs. Finally, influencers' information or recommendations may not be effective or may sometimes cause dissatisfaction (Colgate and Lang 2001). Based on the condition of customer lifetime value $(t)$, the function to measure the information demand from an influencer is " $\mathrm{f}\left(\right.$ information $\left.^{-t}\right)$, where $t$ is time to consume the brand." Therefore, marketing communication by loyal or expert customers is an effective way to generate awareness and encourage purchase. It is more beneficial, according to trust and commitment theory, since customers' role as coproducers has no hidden interest (Baxter and Braithwaite, 2008; Forrester 2018).

\section{Discussion, limitations, and future research direction}

Most studies in the era of information technology until the age of social media communication channels tend to study only the benefits of customer communication, influencers and mutual information (Vargo and Lusch 2004; Rizcky et al. 2014; Innovators 2020). In the $5 \mathrm{G}$ era, such communication has become a common channel, and customers are increasingly using this channel. With the support of technology and having a consumer experience, customers can use communication to recommend or design products to suit themselves (Füller 2010; Ramaswamy 2009). The most popular method is posting a message on a brand fan page as social communication. Marketing where a blogger or reviewer is hired to present the product has reached a saturation point because the direct experience is more realistic than the influencer (Yoo et al. 2010; Majchrzak et al. 2013). Consequently, the influencer who cannot generate new content will become trash, and the flow of feedback from these influencers is starting to become unpopular (Holt 2002). The moderating role of the influencer variable in the path between the coproducers and mutual influencer factors is a crucial issue in marketing and conducting a new marketing strategy. A message post that reflects customers' opinions of the people that consume the same brand product is a good way to extract their real needs. Customers can express their needs freely and cheaply. The findings from this research offer two theoretical contributions. First, expectancy theory affects the role of customers as coproducers, and the second is that trust and commitment theory affect customers' perceptions of influencers (Ang and Buttle 2006).

Previously marketing studies confirmed the conceptual framework using questionnaires. The rigidity of using this instrument is time consuming for self-assessment, and the clarity of the questions and the factual answers may be rigid. Thus, using message posts from a social community is a new way to investigate the actual behaviour and expectations of customers to acquire the product with the right fit. The study found that text processing can be applied to explore the marketing content for testing the hypothesis.

Moreover, there are two contributions of the study during the COVID-19 crisis: selecting a blogger/reviewer that has a good brand experience can support potential customers and enhancing the UX design (user design) can support customer creation. Additionally, the customer experience should enhance mutual information as a firm's intangible asset. Social capital or soft assets are not only an individual 
property but also a community property. Collective social capital emphasizes social capital as a collectively produced and owned good from which the entire community could benefit. The paradigm shift of mutual information to social capital indicates the significance of coproducers and knowledge sharing. It is seen as a macro-level good or a property of a group, a community, or a nation. In addition, this idea was supported by Ramaswamy (2009) in a study on leading the transformation of value to cocreation.

The comparison of the model in Fig. 4 (influencer as the moderator) shows that the indirect effect of influencer as the moderator decreases the effect of mutual information on customer value 0.261 to 0.256 and decreases the effect of coproducers on mutual information from 0.609 to 0.349 . This led to the question that the person who is promoted to be an influencer has the highest consumption experience to establish trust in the community or she/he has only a commercial agenda. In addition, this negative effect has supported Jacobsen's work. Our findings further suggest that in the age of a virtual social community, a firm transforming proactive customers into influencers cultivates management. This strategy not only gives customers/consumers greater access to information but also increases their motivation and ability to consume brands. In general, the perception is that an influencer is a leader who is more innovative, creative, involved, and familiar with the products and has more experience and expertise than the average user. Moreover, the influencer has the ability to generate more interesting content and contribute to trusting relationships. Many firms promote their brands by paying movie stars or celebrities as influencers. Influencers may who have a good-looking image but may lack the ability and knowledge to persuade consumers to buy products. Our findings on the negative interaction between influencers and coproducers supports the distrust of ridiculous messages or information overload. Based on the commitment-trust theory, influencers' role led to the question of whom to trust or distrust has become an increasingly important aspect in social online networks. As a customer encounters much user-generated content each day, evaluating trustworthiness has become continuous.

This finding indicates that a marketer cannot use influencer marketing in the traditional technology disruption era, unless the influencers should generate consistently delivers satisfactory and high-quality content. Therefore, competency influencers are trusted to their expertise and professional and academic affiliations.

The research does have several limitations. The experimental data, which described specific brands in the dessert, food, and beverage groups and led to the knowledge gained, may not cover other groups of goods or services that differ in consumption. Moreover, the data obtained from the Thai message posts must be pre-processed with word segmentation, word relevance, identification, and transformation, which could result in some errors. Noise is the first barrier to confront since customers/consumers favour using letter, symbol, and emoji icons instead of language; therefore, we add the transformation step before preparation. The final limitation is that the message posts must cover the variables in the framework. However, collecting data from message posts is more advantageous in dimensions of flexibility and reality because Thai customers preferred to recommend or suggest via social media more than face-to-face interaction.

Since our research finds positive effects of coproducers on mutual information and customer value, future research should explore other factors to enhance mutual information. In addition to our experience with text processing in this research, we will consider how to extract the features from message posts and apply them to analyses using structural equation modelling (SEM). Due to the research results, when exploring the new marketing content, we should investigate the relationship between customer experience management and customer coproducer management. With the integration of experience and coproducer management, further research will benefit the creation of innovative products and services that respond to customers exactly using technology deployment.

\section{References}

Ahearne, Michael, C.B. Bhattacharya, and Thomas Gruen. 2005. Antecedents and consequences of customer-company identification: Expanding the role of relationship marketing. Journal of Applied Psychology 90 (3): 574-585.

Anderson, E.R. 1973. Consumer dissatisfaction: The effect of disconfirmed expectancy on perceived product performance. Journal of Marketing Research 10: 38-44.

Ang, L., and F. Buttle. 2006. Customer retention management processes-A quantitative study. European Journal of Marketing 40 (1): 83-99.

Ansari, A., and C.F. Mela. 2003. E-customization. Journal of Marketing Research 40 (2): 131-145.

Archer, E., I.M. Park, and J. Pillow. 2013. Bayesian and quasi-Bayesian estimators for mutual information from discrete data. Entropy 15 (12): $1738-1755$.

Bagozzi, R.P., and U.M. Dholakia. 2006. Antecedents and purchase consequences of customer participation in small group brand communities. International Journal of Research in Marketing 23: 45-61.

Barney, Jay B. 1990. The debate between traditional management theory and organizational economics. Academy of Management Review 15 (3): 382-394.

Bart, Yakov, Venkatesh Shankar, Fareena Sultan, and Glen L. Urban. 2005. Are the drivers and role of online trust the same for all web sites and consumers? A large-scale exploratory empirical study. Journal of Marketing 69 (4): 133-152.

Baxter, Leslie A., and Dawn O. Braithwaite. 2008. Engaging theories in interpersonal communication multiple perspectives. Thousand Oaks: SAGE Publications, Inc. 
Bettman, J. 1979. Reviewed work: An information processing theory of consumer choice by James R. Bettman Review by: Ivan Ross. Journal of Marketing 43(3): 124-126.

Bhandari, Humnath, and Kumi Yasunobu. 2009. What is social capital? A comprehensive review of the concept. Asian Journal of Social Science 37 (3): 480-510.

Bilig, M.S. 2000. Institutions and culture: Neo-Weberian economic anthropology. Journal of Economic Issues 34 (4): 771-778.

Blau, P.M. 1964. Exchange and power in social life. New York: Wiley.

Bobkowski, Plotr S. 2015. Sharing the news: Effects of informational utility and opinion leadership on online sharing. Journalism and Mass Communication Quarterly 92: 320-345.

Bolton, R.N., K.N. Lemon, and P.C. Verhoef. 2004. The theoretical underpinnings of customer asset management: A framework and propositions for future research. Journal of the Academy of Marketing Science 32 (3): 271-292.

Bronnenberg, Bart J., Jun B. Kim, and Carl F. Mela. 2016. Zooming in on choice: How do consumers search for cameras online? Marketing Science 35 (5): 693-712.

Burns, T. 1973. A structural theory of social exchange. Acta Sociologica 16: 188-208.

Business Insider. 2020. Influencer Marketing: Social media influencer market stats and research for 2021. Insider report, 6 January. https://www.businessinsider.com/influencer-marketing-report. Accessed 12 Oct 2020.

Chi, K.H., H.R. Yeh, and M.H. Huang. 2009. The Influence of advertising endorser, brand image, brand equity, price promotion on purchase intention: The mediating effect of advertising endorse. http://www.jgbm.org/page/29\%20Ming\%20Wei\%20Huang\%20. pdf. Accessed 12 Oct 2020.

Chu, S.-C., and Y. Kim. 2011. Determinants of consumer engagement in electronic word-of-mouth (eWOM) in social networking sites. International Journal of Advertising 30 (1): 47-75.

Colgate, M., and B. Lang. 2001. Switching barriers in consumer markets: An investigation of the financial services industry. Journal of Consumer Marketing 18 (4): 332-347.

de Vries, Lisette, Sonja Gensler, and Peter S.H.. Leeflang. 2012. Popularity of brand posts on brand fan pages: An investigation of the effects of social media marketing. Journal of Interactive Marketing 26: 83-91.

Dholakia, U.M., R.P. Bagozzi, and L.K. Pearo. 2004. A social influence model of consumer participation in network- and smallgroup-based virtual communities. International Journal of Research in Marketing 21: 241-263.

Evanschitzky, H., and M. Wunderlich. 2006. An examination of moderator effects in the four-stage loyalty model. Journal of Service Research 8 (4): 330-345.

Foong, L.S., and R. Yazdanifard. 2014. Celebrity endorsement as a marketing tool. Global Journal of Management and Business Research: e-Marketing 14 (4): 37-40.

Forrester, Joele. 2018. $47 \%$ of consumers fatigued by repetitive influencers. bazaarvoice.com report, 3 August. https://www.bazaa rvoice.com/uk/press/content-called-out-47-of-consumers-fatig ued-by-repetitive-influencers/. Accessed 12 Aug 2020.

Franke Merle, A., J.-L. Chandon, E. Roux, and F. Alizon. 2010. Perceived value of the mass customized product and mass customization experience for individual consumers. Production and Operations Management 19 (5): 503-514.

Freberg, K., K. Graham, K. McGaughey, and L.A. Freberg. 2011. Who are the social media influencers? A study of public perceptions of personality. Public Relations Review 37: 90-92.

Füller, J. 2010. Refining virtual co-creation from a consumer perspective. California Management Review 52 (2): 98-122.

Gupta, S., D.R. Lehman, and J.A. Stuart. 2004. Valuing customers. Journal of Marketing Research 20: 7-18.
Harrigan, N., P. Achananuparp, and E.-P. Lim. 2012. Influentials, novelty, and social contagion: The viral power of average friends, close communities, and old news. Social Networks Analysis and Mining 34: 470-480.

Hayes, A.F. 2013. Introduction to mediation, moderation, and conditional process analysis: A regression-based approach. New York: Guilford Press.

Hayes, A.F. 2016. The process macro for SPSS and SAS. http://proce ssmacro.org/index.html/. Accessed 12 Oct 2017.

Hille, P., G. Walsh, and M. Cleveland. 2015. Consumer fear of online identity theft: Scale development and validation. Journal of Interactive Marketing 30: 1-19.

Hogan, John E., Katherine N. Lemon, and Barak Libai. 2003. What is the true value of a lost customer? Journal of Service Research 5 (3): 196-208.

Holt, D.B. 2002. Why do brands cause trouble? A dialectical theory of consumer culture and branding. Journal of Consumer Research 29 (1): 70-90.

Hollebeek, Linda D., and Keith Macky. 2019. Digital content marketing's role in fostering consumer engagement, trust, and value: Framework, fundamental propositions, and implications. Journal of Interactive Marketing 45: 27-41.

Homburg, C., and A. Giering. 2001. Personal characteristics as moderators of the relationship between customer satisfaction and loyalty: An empirical analysis. Psychology and Marketing 18 (1): 43-66.

Hovland, C.E., and I.L. Janis, and Harold H. Kelley. 1953. Communication and Persuasion; psychological studies of opinion change. New Haven: Yale University Press.

Hsieh, H.F., and S.E. Shannon. 2005. Three approaches to qualitative content analysis. Qualitative Health Research 15 (9): 1277-1288.

Hsieh, Sara A., and Aihwa Chang. 2016. The psychological mechanism of brand co-creation engagement. Journal of Interactive Marketing 33: 13-26.

Innovators. 2020. Some examples of co-creation that bring brand and consumer together. Innovators report. https://www.ideas4alli nnovation.com/innovators/examples-cocreation-consumers/. Accessed 12 Oct 2020

Iurillo, Olivia. 2019. 6 Dangers of influencer marketing. Social Media report, 11 July. https://www.socialmediatoday.com/news/6-dange rs-of-influencer-marketing/558493/. Accessed 12 Oct 2020.

Jones, M.A., D.L. Mothersbaugh, and S.E. Beatty. 2002. Why customers stay: Measuring the underlying dimensions of services switching costs and managing their differential strategic outcomes. Journal of Business Research 55 (6): 441-450.

Kuchmaner, Christina A., Jennifer Wiggins, and Pamela E. Grimm. 2019. The role of network embeddedness and psychological ownership in consumer responses to brand transgressions. Journal of Interactive Marketing 47(3): 129-143.

Kumar, R., J. Novak, and A. Tomkins. 2010. Structure and evolution of online social networks. In Link mining: Models, algorithms, and applications, 337-357. New York: Springer.

Lambe, C. Jay., C. Michael. Wittmann, and Robert E. Spekman. 2001. Social exchange theory and research on business-to-business relational exchange. Journal of Business-to-Business Marketing 8 (3): $1-36$.

Lee, J.S. 2017. The impact of celebrity endorser attachment and endorser-product-match-up on credibility, attitude, and purchase intense. PhD Dissertation, University of Alabama. https://ir.ua. edu/handle/123456789/3423. Accessed 12 Oct 2020.

Lilien, Gary L., Rangaswamy Arvind, and Bruyn Arnaud De. 2017. Principles of marketing engineering, 3rd ed. State College: DecisionPro, Inc. 
Lim, Radzol, and Wong Cheah. 2017. The impact of social media influencers on purchase intention and the mediation effect of customer attitude. Asian Journal of Business Research 7 (2): 19-36.

Lim, Xin Jean, Aifa Rozaini Mohd Radzol, Jun-Hwa Cheah, and Mun Wai Wong. 2017. The impact of social media influencers on purchase intention and the mediation effect of customer attitude. Asian Journal of Business Research 7(2): 19-36. https://www. researchgate.net/publication/321832168_The_Impact_of_Social_ Media_Influencers_on_Purchase_Intention_and_the_Mediation_ Effect_of_Customer_Attitude. Accessed 5 Mar 2019.

Lin, Tung Ching, Hsing Kenny Cheng, and Sheng Wu. 2004. To share knowledge or not to share: A social exchange theory perspective of virtual team members' behavior. Knowledge Economy and Electronic Commerce 10: 34-56. https://www.academia.edu/ 12598059/To_Share_Knowledge_or_Not_to_Share_A_Social_ Exchange_Theory_Perspective_of_Virtual_Team_Members_ Behavior. Accessed 5 Aug 2019.

Liu-Thompkins, Y., and M. Rogerson. 2012. Rising to stardom: An empirical investigation of the diffusion of user-generated content. Journal of Interactive Marketing 26: 71-82.

Magi, A. 2003. Share of wallet in retailing: The effects of customer satisfaction, loyalty cards and shopper characteristics. Journal of Retailing 79 (2): 97-106.

Majchrzak, A., S. Faraj, G.C. Kane, and B. Azad. 2013. The contradictory influence of social media affordances on online communal knowledge sharing. Journal of Computer-Mediated Communication 19 (1): 38-55.

Mathwick, C. 2006. Building loyalty by sponsoring virtual peer-to-peer problem solving (P3) communities, 211-212. American Marketing Association, Summer. https://www.ama.org/wp-content/uploa ds/2019/02/2006-ama-summer-proceedings.pdf. Accessed 12 Sep 2020.

Mittal, V., and W.A. Kamakura. 2001. Satisfaction, repurchase intent, and repurchase behavior: Investigating the moderating effect of customer characteristics. Journal of Marketing Research 38 (1): 131-142.

Nambisan, S., and R.A. Baron. 2007. Virtual customer environment: Testing a model of voluntary participation in value co creation activities. Journal of Product Innovation Management 26 (4): 388-406.

Nambisan, S., and P. Nambisan. 2008. How to profit from a better virtual customer environment. MIT Sloan Management Review 49(3): 53-61. https://cpb-us-w2.wpmucdn.com/sites.uwm.edu/ dist/8/147/files/2019/11/nambisan-nambisan-SMR-2008.pdf. Accessed 12 Aug 2020.

Olsen, S.O., J. Wilcox, and U. Olson. 2005. Consequences of ambivalence on satisfaction and loyalty. Psychology and Marketing 22 (3): 247-269.

Porter, C.E., and N. Donthu. 2008. Cultivating trust and harvesting value in virtual communities. Management Science 54 (1): 113-128.

Pradhan, D., I. Duraipandian, and D. Sethi. 2016. Celebrity endorsement: How celebrity-brand-user personality congruence affects brand attitude and purchase intention. Journal of Marketing Communications 22 (5): 456-473.

Prahalad, C., and V. Ramaswamy. 2004. Co-creation experiences: The next practice in value creation. Journal of Interactive Marketing 18 (3): $5-14$
Ramaswamy, V. 2009. Leading the transformation to co-creation of value. Strategy and Leadership 37 (2): 32-37.

Rizcky, M., S. Maulana, and Popy Rufaidah. 2014. Co-creation of small-medium enterprises. Procedia: Social and Behavioral Sciences 115: 198-206.

Rodriguez, Michael, and Stefanie Boyer. 2020. The impact of mobile customer relationship management (mCRM) on sales collaboration and sales performance. Journal of Marketing Analytics 8: $137-148$.

Sheth, J.N., B.I. Newman, and B.L. Gross. 1991. Why we buy what we buy: A theory of consumption values. Journal of Business Research 22 (2): 159-170.

Smart Insights. 2017. Key influencer marketing trends for 2017, 12 January. http://www.smartinsights.com/online-pr/influencer marketing/keyinfluencer-marketing-trends-2017/. Accessed 15 Aug 2019.

Soltani, Zeynab and Nima Jafari Navimipouret 2018. Customer relationship management mechanisms: A systematic review of the state of the art literature and recommendations for future research. Computers in Human Behavior 61: 667-688

Uzunoğlu, E., and S.M. Kip. 2014. Brand communication through digital influencers: Leveraging blogger engagement. International Journal Information Management 34: 592-602.

van Knippenberg, D., and M.C. Schippers. 2007. Work group diversity. Annual Review of Psychology 58: 515-541.

Vargo, S., and R. Lusch. 2004. Evolving to a new dominant logic for marketing. Journal of Marketing 6: 1-17.

Vargo, S., P. Maglio, and M. Akaka. 2008. On value and value co-creation: A service systems and service logic perspective. European Management Journal 26: 145-152.

Walsh, G., H. Evanschitzky, and M. Wunderlich. 2008. Identification and analysis of moderator variables: Investigating the customer satisfaction-loyalty. https://doi.org/10.1108/03090560810891109. Accessed 5 Aug 2019.

Weiss, R. (2014). Influencer Marketing. How word-of-mouth marketing can strengthen your organization's brand. Marketing Health Services 34(1): 16-17.

Wikström, Solveig. 1996. The customer as co-producer. European Journal of Marketing 30 (4): 6-19.

Yi, Youjae, and Taeshik Gong. 2013. Customer value co-creation behavior: Scale development and validation. Journal of Business Research 66: 1279-1284.

Yoo, Y., O. Henfridsson, and K. Lyytinen. 2010. Research commentary-The new organizing logic of digital innovation: An agenda for information systems research. Information Systems Research 21 (4): 724-735.

Publisher's Note Springer Nature remains neutral with regard to jurisdictional claims in published maps and institutional affiliations.

Intaka Piriyakul Assistant Professor, Faculty of Business Administration for Society, Srinakharinwirot University, Thailand, B.E. (Computer), M.Ec. (Business Economic) and DBA (Marketing).

Rapepun Piriyakul Associate Professor, Faculty of Science, Ramkhamhaeng University, Thailand. B.Sc. (Mathematics), M.Sc. (Statistics) and Ph.D. (Computer Engineering). 